\title{
O CAPITAL CULTURAL E A PRODUÇÃO DAS DESIGUALDADES ESCOLARES CONTEMPORÂNEAS
}

Maria Alice Nogueira I

I Universidade Federal de Minas Gerais (UFMG), Belo Horizonte (MG), Brasil; malicen@terra.com.br

\section{Resumo}

O objetivo deste artigo é refletir sobre o uso do conceito de capital cultural na explicação das desigualdades escolares contemporâneas. Partindo de dois balanços recentes sobre o uso do conceito no universo científico de língua inglesa e na literatura sociológica francófona, o texto tenta responder às seguintes questões: a posse da riqueza cultural ainda é um trunfo escolar decisivo para a obtenção do êxito escolar? Em que medida isso ainda ocorre após décadas de profundas transformações sociais e educacionais? A análise evidenciou que: (i) as práticas culturais consagradas são hoje menos rentáveis e menos transmissíveis do que no passado; (ii) os investimentos econômicos dos pais têm se mostrado cada vez mais um elemento impulsionador do sucesso escolar dos filhos.

\section{DESIGUALDADE SOCIAL • HERANÇA CULTURAL • DESIGUALDADE EDUCACIONAL・} RENDIMENTO ESCOLAR

\section{CULTURAL CAPITAL AND THE PRODUCTION OF CONTEMPORARY SCHOOL INEQUALITIES}

\section{Abstract}

The aim of this article is to reflect on the use of the concept of cultural capital in explaining contemporary school inequalities. Starting from two recent reviews of the use of the concept among English-speaking researchers and in the francophone sociological literature, the article seeks to answer the following questions: is the possession of cultural wealth still a decisive asset for achieving school success? To what extent does that still occur after decades of deep social and educational changes? Our analysis showed that: (i) established cultural practices are now less profitable and less transferable than in the past; (ii) parents' financial investments have increasingly emerged as a driving force for their children's school success.

SOCIAL INEQUALITY • CULTURAL HERITAGE • EDUCATION INEQUALITY • ACHIEVEMENT 


\section{EL CAPITAL CULTURAL Y LA PRODUCCIÓN DE LAS DESIGUALDADES ESCOLARES CONTEMPORÁNEAS}

\section{Resumen}

El objetivo de este artículo es reflexionar sobre el uso del concepto de capital cultural en la explicación de las desigualdades escolares contemporáneas. Partiendo de dos recientes balances sobre el uso del concepto en el universo científico del idioma inglés y en la literatura sociológica francófona, el texto intenta contestar las siguientes preguntas: ¿la posesión de la riqueza cultural todavía es un activo escolar decisivo para obtener el éxito escolar? ¿En qué medida ello aún ocurre después de décadas de profundas transformaciones sociales y educativas? El análisis puso de manifiesto que: (i) las prácticas culturales consagradas son en la actualidad menos rentables y menos transmisibles que en el pasado; (ii) las inversiones económicas de los padres se han mostrado cada vez más un elemento que impulsa el éxito escolar de los hijos.

DESIGUALDAD SOCIAL • HERENCIA CULTURAL・DESIGUALDAD EDUCATIVA・RENDIMIENTO

\section{LE CAPITAL CULTUREL ET LA PRODUCTION DES INÉGALITÉS SCOLAIRES CONTEMPORAINES}

\section{Résumé}

L'objectif de cet article est de réfléchir à propos de l'utilisation du concept de capital culturel pour expliquer les inégalités scolaires contemporaines. À partir de deux bilans récents sur l'utilisation du concept dans le monde scientifique anglophone et dans la littérature sociologique francophone, le texte tente de répondre aux questions suivantes : la possession de biens culturels reste-t-elle un atout scolaire décisif pour la réussite scolaire ? Dans quelle mesure cela se produit encore après des décennies de profondes transformations sociales et éducatives? L'analyse a montré que : (i) les pratiques culturelles consacrées sont aujourd'hui moins rentables et transmissibles que par le passé; (ii) les investissements économiques des parents deviennent de plus en plus un élément moteur de la réussite scolaire des enfants.

INÉGALITÉ SOCIALE • HÉRITAGE CULTUREL・INÉGALITÉ EN ÉDUCATION • RENDEMENT 
IVERSOS AUTORES, NO CAMPO DA SOCIOLOGIA DA EDUCAÇÃO, TÊM ARGUMENTADO que, no alvorecer do século XXI, é preciso revisar para baixo o peso da herança cultural nos processos de produção das desigualdades de desempenho escolar, em razão das mudanças sociais e sociológicas ocorridas desde o momento de criação desse conceito, há mais de cinco décadas. ${ }^{1}$

Para iniciar essa discussão, cabe relembrar rapidamente a origem e a trajetória do conceito de “capital cultural”, cunhado pelo sociólogo Pierre Bourdieu, na França dos anos 1960-1970, como ferramenta analítica que pudesse dar conta das fortes e persistentes disparidades de oportunidades educacionais entre as diferentes classes sociais. Seu pressuposto era o de que os bens culturais herdados dos pais atuariam com mais força do que as posses econômicas da família nos destinos escolares dos indivíduos. Desde então, o conceito tornou-se central na Sociologia da Educação, atuando como um princípio maior de explicação das (altas) taxas diferenciais de sucesso escolar de acordo com o meio social do aluno. ${ }^{2}$

Entretanto pesquisas recentes vêm nos convidando a revisitar o potencial do conceito, à luz das profundas transformações pelas quais vêm passando, a um só tempo, o cenário sociocultural e educacional contemporâneo, as condições de empregabilidade das novas gerações e as novas problemáticas colocadas pela literatura sociológica atualmente. Este tex to se propõe a isso, por meio de análise documental de material bibliográfico publicado na última década.

Para tanto, partirei de dois balanços recentes sobre a questão. $\mathrm{O}$ primeiro examina o uso do conceito no universo científico de língua inglesa (Davies \& Rizk, 2018); o segundo, por sua vez, explora a literatura sociológica de expressão francófona (Draelants \& Balllatore, 2014); cada um deles obedece a objetivos relativamente distintos, embora muito intersectados.

\section{caráter compósito e flexível do conceito}

Partindo do pressuposto de que os bens econômicos, embora bem mais visíveis, não constituem a única forma de riqueza que fundamenta a divisão da sociedade em classes sociais, Bourdieu defendia que as diferenças no estilo de vida, isto é, na maneira de utilizarmos os bens materiais, engendram distinções simbólicas importantes entre os indivíduos. Essas distinções estão associadas à posse de bens culturais considerados "legítimos", porque válidos na escala da sociedade como um todo, embora sejam produtos intelectuais das classes dominantes, mas com o poder de se impor e de se fazer reconhecer por todos. Para o autor, essa forma de riqueza abarcada sob a expressão de "capital cultural" pode existir em três estados (Bourdieu, 1998): 1) incorporado, porque se impregna em nossos corpos (posturas corporais, esquemas mentais, competências linguísticas, etc.); 2) objetivado, porque se materializa em objetos concretos que simbolizam a cultura dominante (livros, obras de arte, etc.); 3) institucionalizado, porque confere reconhecimento institucional (o diplo$\mathrm{ma}$ ) à posse de competências culturais.

1 Conferir, em particular, Nogueira (2008).

2 Para uma discussão mais ampla das origens e fundamentos do conceito, ver Nogueira (2017). Por ora, lembro apenas que ele traz em sua essência a ideia de um patrimônio cultural diversificado (estruturas mentais e linguísticas, posturas corporais, disposições estéticas, etc.) que as crianças provenientes de famílias cultas herdariam de seus pais e que supostamente favoreceria seu rendimento escolar. 
Esse caráter abrangente e multifacetado do conceito é visto hoje, por muitos estudiosos, como sua maior força, mas, ao mesmo tempo, sua maior debilidade. Sua fragilidade residiria no uso demasiadamente flexível que ele permite, em razão dessa natureza tão complexa, levando a interpretações e definições bastante diversificadas, segundo a filiação teórica de quem dele se serve. Daí adviriam, segundo alguns autores - sobretudo aqueles que trabalham numa linha mais quantitativa -, dificuldades para a tarefa de mensurar empiricamente o volume do capital cultural: "No seu conjunto, a obra de Bourdieu apresenta um conceito de capital cultural polissêmico, abstrato e de difícil uso em surveys educacionais realizados com vistas ao entendimento da proficiência dos alunos" (Soares \& Collares, 2006, p. 621).

No entanto, essa flexibilidade também pode ser considerada uma virtude, na medida em que propiciou tanto a durabilidade do conceito no tempo como sua extensão no espaço. Com efeito, como explicar o fato de que, décadas depois de sua formulação, tantos pesquisadores, ao redor do mundo, continuem a mobilizá-lo, ressignificá-lo e testá-lo empiricamente com a frequência que se conhece?3

Davies e Rizk (2018), em artigo recente sobre a evolução do uso do conceito de capital cultural na pesquisa educacional norte-americana, defendem a existência de três gerações de pesquisadores, e cada uma delas atribui ao conceito significados relativamente diferentes. A primeira geração - atuante nas décadas de 1970 e início de 1980 e leitora, sobretudo, de obras como Os herdeiros e A reprodução - exalta a criação dessa nova ferramenta conceitual e a encara como mecanismo responsável pela estratificação educacional, ou seja, pelas desigualdades de resultados entre os estudantes, colocando a questão no plano mais amplo da mobilidade social. ${ }^{4}$ A segunda geração - operando do final dos anos 1980 ao início dos anos 2000, inspirada principalmente em obras como A distinção, A nobreza de estado e Homo Academicus - utilizou o conceito em diferentes direções empíricas (quantitativas ou qualitativas), entendendo as vantagens culturais como participação em atividades ditas da alta-cultura (frequência a museus, concertos, bibliotecas, galerias de arte, etc.) e como meio de acesso tanto ao êxito social quanto ao sucesso acadêmico. A terceira geração - em ação a partir dos anos 2000 - tem questionado o papel determinante atribuído à alta-cultura nas avaliações escolares, argumentando que, nas sociedades contemporâneas, novas formas de produção cultural (os meios de comunicação de massa; a emergência do multiculturalismo) e novos modelos parentais de gerir a escolaridade dos filhos (senso do investimento, estratégias educacionais sofisticadas, etc.) vêm também condicionando o êxito escolar, para além da estrita posse da cultura dita legítima. ${ }^{5}$

Após examinar a trajetória do conceito ao longo dessas três gerações, os dois autores se indagam: por que ele tem sido útil por tanto tempo e para tantos estudos empíricos? E respondem que isso se deve à sua "qualidade sintética" (synthetic quality) que combina o pensamento sociológico francês com a tradição das ciências sociais norte-americanas. Além disso, ao insistir no papel da classe social e da luta dos atores sociais por status, agradou tanto a marxistas quanto a weberianos; ao associar as escalas macro e micro de análise, atraiu tanto pesquisadores de orientação quantitativa como aqueles que se servem de métodos qualitativos:

Nossa análise mostra que o uso do conceito tem sido inegavelmente fértil, invocado em centenas de estudos por pesquisadores de grande notoriedade. Mas essa fertilidade provém de sua flexibilidade, de sua adaptabilidade a diferentes gêneros de pesquisa, desde os surveys até a etnografia escolar, a microssociologia ou os estudos de subculturas. (Davies \& Rizk, 2018, p. 350, tradução nossa) ${ }^{6}$

3 Davies e Rizk (2018) lembram que Bourdieu figura na lista dos dez autores mais citados em periódicos da área educacional, e que a seção de Sociologia da Educação da American Sociologial Association instituiu The Pierre Bourdieu Award para premiar os melhores livros na área.

4 Compõem essa primeira geração pesquisadores como J. Karabel, A. H. Halsey e R. Murphy e C. Hurn.

5 A segunda e terceira gerações reúnem autores como P. DiMaggio, A. Lareau e R. Collins.

6 Tradução própria, deste excerto e de todos os demais da mesma obra. No original: "Our review shows that it has been undeniably generative, invoked in hundreds of studies by leading researchers. But this generativity has come from its flexibility, its amenability to very different research genres, from survey research to school ethnographies to micro-sociology to subcultural studies." 
Ainda segundo os autores, o maior mérito do conceito reside em sua capacidade "generativa", isto é, em seu poder de fomentar novos objetos empíricos e pesquisas de diferentes gêneros em diversas áreas do conhecimento, bem como em sua habilidade de promover um código comum entre os pesquisadores. Eles escrevem:

Seu principal benefício tem sido a facilidade de gerar estudos sobre diferentes dimensões da desigualdade educacional, ao mesmo tempo em que fornece aos pesquisadores uma linguagem comum na investigação de questões similares. (Davies \& Rizk, 2018, p. 351) ${ }^{7}$

São essas as razões apontadas para o fato de o conceito de capital cultural ter atravessado fronteiras e se introduzido "em um vasto grupo de contextos nacionais, além da França e dos Estados Unidos" (Davies \& Rizk, 2018, p. 350).

No entanto, na opinião dos autores, "essa mesma flexibilidade que permitiu o florescimento do conceito de capital cultural também pode ser vista como uma fraqueza" (Davies \& Rizk, 2018, p. 350), pois, ao contemplar um arco tão amplo de tradições científicas, o conceito acabou por comprometer, ao mesmo tempo, sua clareza conceitual e sua capacidade de verificação empírica. Esses dois elementos teriam prejudicado tanto o aprofundamento e a unificação da teorização quanto a formação de um corpus coerente de dados empíricos sobre as desigualdades educacionais.

Contudo, ao final do extenso exame realizado pelos dois autores, a balança parece pender para o lado positivo, com base no argumento de Davies e Rizk (2018, p. 351) de que "a duradoura utilidade de um conceito como o de capital cultural reside mais em sua capacidade de estimular uma variedade de estudos empíricos de qualidade do que em provocar consistência conceitual e verificação empírica replicada". ${ }^{10}$

Por fim, Davies e Rizk arriscam as previsões de que: (i) o conceito continuará sofrendo metamorfoses, em consonância com as mudanças no universo educativo; (ii) as futuras gerações de pesquisadores seguirão empregando o conceito na forma de uma "pluralidade de métodos e de teorias"11 (2018, p. 351).

Por sua vez, sociólogos de língua francesa também têm se debruçado sobre a trajetória e usos do conceito de capital cultural, em particular pela comunidade científica francófona. Dentre eles, destaca-se o trabalho de Draelants e Ballatore (2014), que realiza uma revisão de literatura à guisa de balanço crítico do conceito, considerado uma das noções centrais (concepts majeurs) da Sociologia da Educação. Os autores chegam até mesmo a afirmar que:

O conceito de capital cultural ... faz parte de uma espécie de fundo comum dos sociólogos da educação francófonos que a ele recorrem de modo quase que automático [quasi réflexe] para explicar o papel da escola na reprodução das desigualdades sociais. (Draelants \& Ballatore, 2014, p. 116, tradução minha) ${ }^{12}$

Nesse caso, as interrogações principais dos autores são: tal conceito ainda é pertinente na realidade social e escolar contemporânea? Se sim, em que condições e "segundo qual definição"? Questões muito próximas das indagações dos autores de língua inglesa, com o intento de "abrir a caixa preta" do conceito de capital cultural (Draelants \& Ballatore, 2014, p. 115-116).

Mas, dessa feita, a resposta passará por um retorno crítico ao conceito, feito à luz de duas dimensões: (i) uma dimensão sociológica relativa à sua apropriação por parte da atual geração de pesquisadores; (ii) uma dimensão social referente a seu papel na conjuntura atual de funcionamento dos sistemas de ensino.

\footnotetext{
7 No original: "its key benefit has been its facility to generate studies of different dimensions of educational inequality, while still providing researchers with a common language to pursue similar questions".

8 No original: "a wide array of national contexts beyond France and United States."

9 No original: "the same flexibility through which cultural capital has flourished can also be seen as a weakness".

10 No original: "the lasting utility of a concept like cultural capital is a capacity to stimulate a variety of quality empirical studies rather than prompting conceptual consistency and repeated empirical verification."

11 No original: "plurality of methods and theories".

12 No original: "Le concept de capital culturel ... fait partie d'une sorte de fonds commun des sociologues de l' éducation francofones qui y recourent de manière quasi réflexe pour expliquer le rôle de l'école dans la reproduction des inégalités sociales".
} 
No que diz respeito à primeira dimensão, Draelants e Ballatore (2014) discutem a extensão da definição do conceito de capital cultural. Para eles, o caráter compósito e multifacetado do conceito como exposto anteriormente - tem levado a interpretações diversificadas. Dessa maneira, constata-se na atualidade (tanto entre os pesquisadores, quanto entre os educadores) uma grande dubiedade entre:

- Uma definição "minimalista", que reduz o capital cultural a seu estado institucionalizado, ou seja, ao nível de escolaridade do detentor, desprezando todas as outras formas de recursos culturais. Contando com um confortável indicador (o diploma) que lhe confere um caráter altamente operatório, constitui a abordagem mais frequentemente utilizada nas pesquisas quantitativas, exercendo, sobretudo, a função de variável estatística. ${ }^{13}$

- Uma definição "restrita”, que associa fortemente o capital cultural à alta-cultura, ou seja, à cultura socialmente legitimada que é produzida e/ou acumulada em laboratórios, museus, bibliotecas, conservatórios, etc. Predominante no mundo anglo-saxão, ${ }^{14}$ essa definição se reveste igualmente de vantagens operacionais, na medida em que opera o trânsito da conceitualização para variáveis comodamente mensuráveis, como os índices de leitura, a frequência a museus, teatros, concertos etc. No entanto, por ser incapaz de captar as "sutilezas" da apropriação pelos sujeitos das obras de cultura (o que se lê e a que se assiste? De que modo? Por quais motivos? Com quais efeitos?), ela é criticada por aqueles que a acusam de "simplificar" ou de "trair" o pensamento de Bourdieu, ao desprezar a relação dos sujeitos com suas práticas culturais (mais ou menos diletantes, mais ou menos reflexivas, etc.).

- Uma definição "alargada”, que extrapola o exercício de práticas culturais legítimas e se estende às disposições dos sujeitos em matéria de bens culturais e a seus efeitos. Predominante entre os sociólogos de língua francesa, essa definição seria mais fiel às ideias de Bourdieu, porque não toma o conceito como sinônimo de propriedade ou atributo de alguém, mas o encara como um processo de "in-corpo-ração" à própria pessoa de seu detentor, por exemplo, na forma de esquemas mentais (raciocínio lógico, capacidade analítica, espírito crítico), de estruturas linguísticas (habilidade interpretativa e argumentativa). Além da dificuldade de operacionalização, a fragilidade dessa definição residiria justamente em seu caráter amplo e abstrato, que faz dela um conceito vago em que cabem elementos bastante díspares, e que, portanto, "perde necessariamente, em compreensão, aquilo que ganha em extensão"15 (Draelants \& Ballatore, 2014, p. 119, tradução minha).

No que tange à segunda dimensão da tarefa de efetuar um balanço crítico do conceito de capital cultural, Draelants e Ballatore (2014) se debruçam sobre as dinâmicas contemporâneas de reprodução social pela escola e passam a interrogar o papel determinante dos bens culturais legítimos - tal como estabelecido por Bourdieu - no sucesso escolar. Eles se perguntam, com efeito, se a "rentabilidade escolar do capital cultural" não "estaria em declínio"16 (p. 120, tradução minha) no contexto atual. Os argumentos que sustentam e justificam tal indagação baseiam-se, por sua vez, no exame de dois "postulados discutíveis" na atualidade, a saber:

1. Subsistiria ainda hoje uma cultura legítima? Nas últimas décadas, não estaria ela perdendo muito de seu valor para novos repertórios culturais como a cultura de massa e a indústria cultural? Consequentemente, não estaria perdendo também seu poder de dominação, ou

\footnotetext{
13 Para uma crítica dos limites dessa definição do conceito, ver o artigo de Serre (2012).

14 Segundo Draelants e Ballatore (2014), DiMaggio foi o sociólogo que mais difundiu, no universo anglófono, a definição de capital cultural como highbrow culture.

15 No original : "perd nécessairement en compréhension ce qu'il gagne en extension".

16 No original : "La rentabilité scolaire du capital culturel en déclin?".
} 
seja, sua capacidade de se impor a todos como cultura superior? ${ }^{17} \mathrm{O}$ que não significa, contudo, o desaparecimento de hierarquias entre gêneros culturais, nem mesmo de seu poder de classificação e de distinção.

2. Os saberes que a escola atual veicula ainda emanam da cultura erudita, constituindo a matéria-prima dos currículos? Ao que tudo indica, o poder da legitimidade cultural de se impor sobre os conteúdos curriculares vem sendo mitigado em razão de certas transformações sofridas pelo sistema escolar da maioria dos países ocidentais, das quais as mais importantes seriam:

a. a massificação do ensino secundário, e mesmo do ensino superior, que traz a cultura popular e as culturas juvenis (Pasquier, 2005) para dentro da escola, fazendo com que essa instituição deixe de ser um templo reservado aos "herdeiros";

b. a resposta dos docentes ao fenômeno da massificação, ajustando suas práticas pedagógicas e os próprios conteúdos da transmissão escolar a essa nova composição social do alunado; ${ }^{18}$

c. a evolução curricular em si mesma que tem levado a uma maior valorização da ciência e da tecnologia (em detrimento da cultura clássica) e a "novos sistemas de distinção" escolar, como se verá mais à frente.

A partir desses elementos, os autores concluem que, para os defensores de uma definição "restrita" do conceito de capital cultural, há efetivamente declínio da rentabilidade do capital cultural para o êxito escolar, uma vez que, na contemporaneidade: (i) não mais subsistiria uma cultura legítima nitidamente diferenciada da cultura de massa; (ii) a escola constituiria cada vez menos o lócus de inculcação da legitimidade cultural.

No entanto, para aqueles que aderem a uma definição "alargada”, não há que se falar em declínio, pois outras dimensões do capital cultural - desconsideradas ou secundarizadas pelos adeptos da definição "restrita" - garantiriam, sim, benefícios escolares poderosos a seus portadores. Para eles, se a familiaridade com a alta-cultura atua fortemente sobre os resultados escolares, não é porque a escola elege determinados conteúdos culturais (em vias, aliás, de reconfiguração), mas, sobretudo, porque o sistema de ensino produz, requer e valoriza certas disposições cognitivas e comunicacionais (linguísticas) que apenas uma parte do alunado logrou desenvolver no processo de socialização cultural primária.

Por fim, considerando esse debate - "por" ou "contra" a apropriação do conceito - como "pouco produtivo", os autores assim se posicionam: "mais do que tentar arbitrar entre essas duas abordagens, nós escolhemos enfatizar suas complementariedades"19 (Draelants \& Ballatore, 2014, p. 124, 135).

\section{O conceito à prova de novas realidades sociais}

As reflexões desenvolvidas anteriormente deverão servir como pano de fundo para a análise que se segue sobre a atualidade do conceito de capital cultural no que concerne à problemática sociológica clássica das desigualdades educacionais constatadas, incessantemente, entre os diferentes grupos sociais. Em outras palavras, a posse de um determinado tipo de privilégio - a vantagem cultural - constitui trunfo escolar decisivo para aqueles que a detêm? Em que medida isso é real na atualidade? Para discutir essas questões, será examinado, com maior detalhe, um conjunto de transformações sociais e escolares que afetam as sociedades contemporâneas e que parecem atenuar a força e a importância dessa vantagem de ordem simbólica.

\footnotetext{
17 Para Lahire (2004), trata-se do enfraquecimento da crença coletiva na superioridade da alta-cultura. Para Coulangeon (2011), trata-se da emergência de um "ecletismo" das práticas culturais que marca as condutas dos sujeitos contemporâneos.

18 A esse respeito, Coulangeon (2011) assinala o "enfraquecimento da relação de conivência que, tradicionalmente, ligava os docentes aos alunos, dada a relativa homogeneidade social do corpo docente e dos alunos do ensino médio [...]" (p. 286).

19 No original: "Plutôt que de chercher à départager ces deux approches, nous avons choisi de mettre l'accent sur leurs complémentarités".
} 


\section{A massificação escolar e seus efeitos}

Como se sabe, um conjunto de mutações contemporâneas - econômicas, políticas, culturais - levou a expressivas transformações nos sistemas educacionais da maioria dos países ocidentais. A mudança mais profunda diz respeito ao fenômeno - desencadeado a partir do final da Segunda Guerra mundial - de massificação escolar, que consiste na universalização ou, no mínimo, na forte elevação das taxas de cobertura dos diferentes graus de ensino, bem como no prolongamento das trajetórias escolares, atingindo todos os meios sociais, embora de modo desigual. ${ }^{20} \mathrm{Na}$ França, mais recentemente, alguns autores têm falado em uma "segunda massificação escolar", a partir das décadas de 1980 e 1990, afetando especialmente o ensino médio e o superior (Poullaouec \& Lemêtre, 2009). Para o que nos interessa aqui, essa segunda onda traria como novidade uma forte diversificação dos percursos de formação dos jovens e um embaralhamento (brouillage) das hierarquias escolares, obrigando os atores do mundo escolar a "reconsiderar suas atitudes" ${ }^{21}$ (p. 5, tradução minha), sem que os autores se estendam sobre esse último ponto.

Esse fenômeno de forte expansão que vem modificando fortemente a paisagem educacional contemporânea se desdobra em diferentes dimensões, e a primeira delas diz respeito aos próprios conteúdos do ensino. É que a chegada de "novos públicos" - em um sistema anteriormente reservado a determinados grupos sociais ${ }^{22}$ - traz consigo novos repertórios culturais derivados da cultura popular, da indústria cultural, das culturas juvenis, levando a expressivas mudanças nos padrões curriculares, dentre as quais devem ser ressaltadas:

a. A emergência de novas linguagens a exemplo da cultura eletrônico-digital que costumamos opor à cultura escolar tradicional, apontando essa última como fonte de desmotivação e de dispersão dos alunos.

b. O imperativo do multilinguismo, ou seja, as exigências impostas - em uma era de globalização, tanto pelos novos estilos de vida quanto pelo mercado de trabalho - do domínio de idiomas e de certas competências em matéria de comunicação.

c. A necessidade, em nome da empregabilidade, do desenvolvimento de disposições cosmopolitas favorecedoras da mobilidade geográfica. Trata-se de desenvolver aquilo que Murphy-Lejeune (2003) denomina de "capital de mobilidade", que engloba traços de personalidade como autonomia, abertura, adaptabilidade, tolerância à alteridade, demandados daqueles que se destinam a serem "cidadãos do mundo", para usar uma metáfora tão cara ao senso comum e tão presente no discurso das famílias (Nogueira \& Aguiar, 2008). ${ }^{23}$

Tudo isso tem levado a novas formas de distinção escolar e a novos conteúdos do que se considera como excelência escolar. Surgem novas formas de capital cultural, como a cultura digital ou o capital cultural internacional, ${ }^{24}$ que, embora associadas à alta-cultura, não se confundem completamente com ela.

20 Como alerta Van Zanten (2007), é preciso estabelecer uma distinção entre um processo de “massificação" que reside numa expansão "quantitativa" do acesso aos níveis mais elevados do sistema de ensino por parte dos grupos sociais antes deles excluídos, e uma verdadeira "democratização" escolar reservada às classes médias e superiores que desfrutariam de uma ampliação "qualitativa", isto é, de um "acesso real e mais extensivo ao conhecimento" ["un real acceso más extensivo al conocimiento"] (p. 250).

21 No original: "reconsidérer leurs atitudes".

22 É bom lembrar que a nova composição da clientela escolar não se limita à inclusão de alunos originários de grupos socioeconômicos desfavorecidos, mas se estende também a crianças portadoras de necessidades especiais, a menores em conflito com a lei, etc.

23 Igarashi e Saito (2014), em estudo bastante inovador, defendem que o cosmopolitismo pode funcionar como capital cultural em seus três estados. Os autores formulam a hipótese de que o sistema educacional constitui o principal mecanismo de institucionalização desse "novo elemento" do capital cultural, na medida em que ele: (i) legitima o cosmopolitismo como atributo desejável na era global; (ii) o distribui desigualmente entre os diferentes grupos sociais de acordo com sua posse de outros tipos de capital; (iii) o associa ao acesso às posições sociais privilegiadas que demandam atributos fortemente internacionais.

24 A socióloga Anne Catherine Wagner (2003) até mesmo vê no capital cultural internacional um novo princípio de "dominação escolar", porque ele estaria modificando a definição legítima do que é uma boa formação, ao criar novas fontes de legitimidade que se ancoram em uma cultura internacional. Draelants e Ballatore (2014), por sua vez, preferem falar em "uma forma recomposta de capital cultural que se poderia qualificar de capital cultural de tipo internacional" ["une forme recomposée de capital culturel, que l'on pourrait qualifier de capital culturel de type international"] (p. 133). 
No entanto, como alertam Draelants e Ballatore (2014), há aqui uma importantíssima exceção que diz respeito às práticas legítimas de leitura transmitidas e requeridas pela escola, as quais continuam sendo altamente rentáveis no mercado escolar. De fato, como evidencia a literatura sociológica, a leitura continua exercendo um papel fundamental no desempenho escolar. Forma cultural fortemente associada à escrita e às competências linguísticas - que constituem a base da socialização escolar -, ela promove efeitos cognitivos e analíticos capazes de impulsionar o êxito no processo de aquisição do conhecimento.

Em síntese, tudo levaria a crer que as elites escolares são cada vez menos compostas por "herdeiros", no sentido bourdieusiano do termo, e cada vez mais constituídas por "iniciados", no sentido da tese defendida por Draelants (2014), que afirma que nos tempos atuais o pódio escolar é ocupado menos por sujeitos altamente cultivados e eruditos, e mais por indivíduos que detêm trunfos informacionais e estratégicos relativos ao mundo da escola que permitem que eles se orientem particularmente bem no labirinto dos sistemas de ensino contemporâneos. Assim, em vez de uma relação diletante e desenvolta com o conhecimento escolar, os novos iniciados desenvolveriam uma relação mais ativa, mais instrumental e mais consumista com sua vida escolar, como se verá a seguir.

Se o fenômeno da massificação escolar atingiu em cheio a instituição escolar, seus usuários (famílias e alunos) não deixam de sofrer também um grande impacto. Como se sabe, o cenário de reestruturação econômica resultante da globalização engendrou riscos e fortes incertezas no que concerne ao mercado de trabalho, principalmente a instabilidade e a vulnerabilidade da oferta de emprego qualificado, colocando, para os indivíduos, grandes desafios em relação à empregabilidade.

No plano político, a orientação dita neoliberal, dos anos 1980 e 1990, de desregulamentação e de encolhimento do Estado, resultou em reformas dos serviços públicos com ênfase no mercado e na livre escolha por parte dos sujeitos usuários.

$\mathrm{Na}$ esfera da educação, o fenômeno da elevação geral dos níveis de escolaridade teve como efeito mais notável a intensificação da concorrência escolar e da exigência contemporânea de trajetórias escolares cada vez mais longas. De acordo com Dubet (2007), a competição escolar aumenta pelo simples fato de que aumenta o número de competidores, trazendo

duas consequências principais que os professores condenam, mas que a massificação que defendem produziu: a formação de um mercado escolar no próprio seio da escola pública ${ }^{25} \mathrm{e}$ o desenvolvimento do utilitarismo das famílias ... que buscam maior rentabilidade escolar. ${ }^{26}$ (Dubet, 2007, p. 54-55, tradução minha).

Sobre esse último ponto, Dubet afirma que, em um contexto de massificação escolar, as famílias buscarão "legitimamente" para sua prole o trajeto de formação, o estabelecimento de ensino e, até mesmo, a sala de aula que avaliam como os mais eficazes. O autor chama a atenção para o fato de que, em todos os meios sociais, o investimento em educação aumenta, embora de modo e em graus distintos e, também, com efeitos desiguais.

\section{A resposta das famílias à massificação escolar}

Para os pais de alunos, trata-se agora de oferecer aos filhos as melhores oportunidades de êxito, de preferência nos setores mais prestigiosos do sistema de ensino. Eles o farão mediante o emprego de estratégias diversificadas e cada vez mais sofisticadas, dentre as quais são destacadas:

25 Os pesquisadores do tema formularam a noção de "quase-mercado" para dar conta da crescente diferenciação dos estabelecimentos de ensino públicos no que toca a sua imagem/reputação e à consequente disputa por vagas nos estabelecimentos mais bem cotados, por parte das famílias.

26 No original: "dos consecuencias principales que los professores condenan pero que la masificación que defienden ha producido: la formación de un mercado escolar en el seno mismo de la escuela pública, y el desarrollo del utilitarismo de las famílias ... que persiguen la mayor rentabilidad escolar". 
a. As condutas de escolha do estabelecimento de ensino para os filhos. Em seu ato de escolha, os pais investirão, crescentemente, um capital de informações variadas sobre o funcionamento do sistema escolar (resultados exibidos em avaliações sistêmicas, rankings de estabelecimentos publicados na mídia, mas também as chamadas informações "quentes" obtidas em suas redes de relacionamentos, por exemplo), ampliando assim sua habilidade de distinguir entre os diferentes tipos de estabelecimentos de ensino e, no caso dos mais habilitados, até mesmo ajustá-los ao perfil escolar do filho (mais ou menos estudioso, esforçado, etc.).

b. As estratégias de intensivo monitoramento da vida escolar dos filhos, que vão do controle das atividades dos profissionais do ensino e da participação nas instâncias administrativas da escola à ajuda doméstica nos deveres de casa e demais atividades requeridas pela escola. Para isso, os pais de alunos na atualidade não poupam esforços e dispendem tempo e energia em prol do desempenho escolar da prole. Revisitando rapidamente, à luz do cenário atual, a tese bourdieusiana do impacto inexorável (e "osmótico") do capital cultural familiar sobre o sucesso escolar, Meuret (2011) escreve que "as mães burguesas de hoje perdem mais tempo cobrando empenho escolar de suas crianças do que as levando ao teatro". Para ele, "o suor exerce uma função que, sem dúvida, Bourdieu e Passeron já subestimavam, mas que posteriormente aumentou" (p. 460).

c. O recurso a um arsenal de dispositivos (onerosos) de suporte à ação da escola que têm por finalidade municiar o aluno para a "corrida de obstáculos" escolar. Trata-se de um conjunto constituído de materiais paraescolares e de dispositivos de terceirização da ajuda aos pais (aulas particulares, aulas de idiomas e de artes, consultórios de psicopedagogia, empresas especializadas no reforço escolar e no acompanhamento do dever de casa, sessões de coaching, etc.) que Glasman (2011) chamou de uma "escola fora da escola”. Essa programação intensa e contínua que estrutura o tempo extraescolar tem sido tematizada, na pesquisa educacional, sob a expressão de shadow education (Bray, 2009), por ocorrer à sombra do sistema de ensino.

d. O crescente apelo a estratégias de internacionalização da trajetória escolar dos filhos, geralmente por meio dos intercâmbios no exterior que hoje abrangem todos os graus do ensino. Embora o ensino superior continue sendo o nível de ensino mais internacionalizado, ${ }^{27}$ verificam-se atualmente estratégias familiares muito precoces de internacionalização que implicam em escolha de pré-escolas e escolas primárias e secundárias bilíngues ou multilíngues. Tais intercâmbios se fazem, em sua larga maioria, em direção aos países desenvolvidos e de língua inglesa, como num "tropismo" (Darchy-Koechlin \& Van Zanten, 2005).

Como se vê, boa parte dessas estratégias supõe tanto ou mais capital econômico (e social) do que capital cultural. É por isso que o sociólogo da educação inglês Phillip Brown (1990) defende a tese de uma transição - nas últimas décadas do século XX, com o advento das reformas ditas neoliberais - de um regime meritocrático para um regime parentocrático, no qual o sucesso escolar do aluno está cada vez menos baseado em seu mérito e esforços individuais, e cada vez mais nos recursos financeiros e na capacidade estratégica de seus pais de impulsionar sua competitividade escolar.

No universo de língua francesa, diversos sociólogos da educação chegam às mesmas conclusões em suas pesquisas. Agnès Van Zanten (2014), por exemplo, afirma a esse respeito:

A Sociologia da Educação francesa atribuiu, durante muito tempo, uma posição central ao papel do capital cultural; todavia, nossas pesquisas, assim como outros trabalhos mais recentes ... incentivam a revalorizar a influência do capital econômico. Este último permite que os 
grupos mais abastados não só procedam a escolhas no tocante ao local de suas residências ou a estabelecimentos privados com muito boa reputação pouco acessíveis a outros grupos, mas também disponham de trunfos suplementares, mediante pagamento, para apoiar a competição, tais como as aulas particulares ou as estadas linguísticas no exterior (p. 168).

Assim como o sociólogo belga Hugues Draelants (2014), que conclui pelas vantagens atuais dos "detentores de capital econômico", ao invocar "a tendência da excelência escolar de se construir na sombra de atividades para-escolares onerosas como as aulas particulares e os intercâmbios linguísticos no exterior"28 (p. 426, tradução minha).

Nos Estados Unidos, pesquisas realizadas por Sean Reardon (2011) vêm estudando o impacto do fenômeno de aprofundamento das desigualdades econômicas - verificado nos últimos 50 anos naquele país - sobre as desigualdades de escolarização. O autor constata que, se a correlação entre o nível de escolaridade dos pais e os resultados escolares dos filhos permaneceu relativamente estável nos últimos 50 anos, a correlação entre a renda familiar e o desempenho escolar cresceu de modo robusto, levando-o a afirmar que a variável renda é hoje quase tão forte para predizer o desempenho escolar quanto a variável escolaridade dos pais. Para explicá-lo, ele levanta a hipótese de que "os padrões de investimento familiar mudaram diferencialmente durante o último meio século", ${ }^{29}$ fazendo com que as famílias mais favorecidas economicamente invistam atualmente "mais recursos socioeconômicos e sociais" em benefício do "desenvolvimento cognitivo" dos filhos.

\section{À guisa de conclusão}

$\mathrm{O}$ presente texto não pretendeu proceder a um exame do conceito de capital cultural em si mesmo, a exemplo do que realiza Bernard Lahire (2004), em seu livro La culture des individus. O intento deste trabalho foi apenas o de levantar alguns pontos importantes e necessários para uma reflexão sobre o papel que esse conceito (e a realidade empírica que ele designa) pode desempenhar nas análises sociológicas sobre os fundamentos sociais das desigualdades escolares, no momento atual.

Nesse sentido, voltamos à pergunta inicial - formulada na parte introdutória deste artigo sobre a pertinência (ou não) de "revisar para baixo" o peso da herança cultural no desempenho escolar, considerando o cenário social e educacional contemporâneo. A resposta a ela é positiva, na medida em que a análise empreendida: (i) evidenciou que as vantagens culturais stricto sensu se mostram hoje - no plano educacional - menos rentáveis e menos transmissíveis do que parecem ter sido no passado, declinando em favor de novas formas de capital cultural; (ii) constatou que o favorecimento econômico tem se mostrado cada vez mais um elemento facilitador e impulsionador do sucesso escolar, por meio dos mais diferentes investimentos materiais feitos, pelos pais, na escolarização dos filhos.

Por um lado, vimos que o capital cultural em sua definição "restrita" - isto é, como sinônimo de posse da alta-cultura - não mais se mantém como motor inexorável do êxito nos estudos, tanto em função da desvalorização (relativa), em escala societária, das práticas culturais consagradas quanto em razão das dificuldades enfrentadas em sua transmissão de uma geração a outra: nem a escola, nem a família conseguem hoje (se é que um dia conseguiram plenamente) obter êxito completo em sua tarefa de imposição da cultura legítima, por meio dos processos de socialização que lhes são próprios e que se revelam cada vez mais incertos (por exemplo, o esforço de muitos pais e muitos professores para desenvolver nos filhos/alunos o gosto pela leitura).

Por outro lado, quando se toma o conceito de capital cultural em seu sentido amplo, isto é, como sinônimo de disposições culturais e de relação com os bens de cultura, é imperioso constatar que uma fortíssima correlação com o sucesso escolar subsiste, porque determinados modos de socialização familiar

28 No original : "la tendance de l'excellence scolaire à se construire dans l'ombre d'activités parascolaires onéreuses comme les cours particuliers et les séjours linguistiques".

29 No original: "Family investment patterns have changed differentially during the last half-century". 
são indubitavelmente mais favoráveis do que outros à constituição de disposições cognitivas (esquemas mentais, maneiras de pensar e interpretar o mundo físico e social, espírito crítico, capacidade analítica), linguísticas (habilidades de expressão oral e escrita, capacidade argumentativa), comportamentais (liderança, dinamismo, espírito de equipe); todos esses traços valorizados e mesmo requeridos pela escola. Sem falar do capital informacional relativo ao funcionamento dos sistemas de ensino, que está na base das estratégias educativas parentais e de sua propensão a investir no sucesso escolar dos filhos.

Poder-se-ia argumentar, algo que foi feito inclusive em seções anteriores deste texto, que boa parte dessas estratégias parentais visando a pavimentar e incrementar a rota do sucesso escolar dos filhos supõe recursos financeiros, muitas vezes onerosos. No entanto, a própria literatura sociológica vem demonstrando que o consumo de dispositivos e/ou de profissionais paraescolares será tanto mais eficaz para a promoção do êxito escolar quanto mais qualificados culturalmente forem os consumidores e mais informado for seu ato de consumo: saber fazer a escolha certa, na hora certa, pelas razóes apropriadas. Em outras palavras, em se tratando de processos de escolarização, o simples investimento econômico não parece ser o bastante, é preciso que o investidor tenha as condições (culturais) necessárias para que consiga tirar dele o proveito almejado.

Mas se, em matéria de escolarização, o capital econômico ainda guarda alguma dependência do capital cultural, isso não deve ocultar o fato de que o dispêndio financeiro das famílias em prol da causa escolar tem hoje papel relevante e crescente na construção da excelência escolar. Quer se trate de experiências de escolarização em escala internacional, do acesso a instituições de ensino diferenciadas, a dispositivos extraescolares suplementares ou à terceirização do reforço escolar, estamos diante de uma lógica - ainda que limitada - de conversão de recursos econômicos em vantagens escolares. É nesse sentido que a noção de "parentocracia", cunhada por Phillip Brown e mencionada anteriormente, parece ter forte potencial explicativo, para dar conta do atual contexto educacional, na medida em que reúne, numa só ferramenta analítica, tanto a capacidade estratégica derivada do favorecimento cultural quanto os recursos materiais que permitem sua efetivação.

Em suma, tudo leva a crer que - apesar de seu "viés de baixa" - o papel do capital cultural continua sendo decisivo no contexto atual, desde que concebido em seu sentido amplo, que incorpora as novas dinâmicas culturais em curso e a importante mobilização parental contemporânea em favor da transmissão da herança cultural.

\section{Agradecimentos}

Agradeço ao CNPq o apoio a minhas pesquisas. Agradeço também a Tania F. Resende, pelas valiosas sugestões feitas a este texto.

\section{Referências}

Bourdieu, P. (1988). Os três estados do capital cultural. In M. A. Nogueira \& A. Catani (Org.), Escritos de educação (pp. 71-79). Vozes.

Bray, M. (2009). Confronting the shadow education system: What government policies for what private tutoring. UNESCO/International Institute for Educational Planning.

Brown, P. (1990). The 'third wave': Education and the ideology of parentocracy. British Journal of Sociology of Education, 11(1), 65-86.

Coulangeon, P. (2011). Efeitos culturais da educação. In A. Van Zanten (Org.), Dicionário da educação (pp. 284-288). Vozes.

Darchy-Koechlin, B., \& Van Zanten, A. (2005). Introduction: La formation des élites. Revue Internationale d'Education de Sèvres, 39, 19-23. 
Davies, S., \& Rizk, J. (2018). The three generations of cultural capital research: A narrative review. Review of Educational Research, 88(3), 331-365.

Draelants, H. (2014). Des héritiers aux initiés? Note sur les nouvelles modalités de la reproduction sociale par l'école. Social Science Information, 53(3), 403-432.

Draelants, H., \& Ballatore, M. (2014). Capital culturel et reproduction scolaire: Un bilan critique. Revue Française de Pédagogie, 186, 115-142.

Dubet, F. (2007). El declive y las mutaciones de la institución. Revista de Antropología Social, 16, 39-66.

Glasman, D. (2011). Apoio fora da escola. In A. Van Zanten (Org.), Dicionário de educação (pp. 40-42). Vozes.

Igarashi, H., \& Saito, H. (2014) Cosmopolitanism as cultural capital: Exploring the intersection of globalization, education and stratification. Cultural Sociology, 8(3), 222-239.

Lahire, B. (2004). La culture des individus: Dissonances culturelles et distinction de soi. La Découverte.

Meuret, D. (2011). Igualdade e equidade dos sistemas educativos. In A. Van Zanten (Org.), Dicionário de educação (pp. 458-463). Vozes.

Murphy-Lejeune, E. (2003). L'étudiant européen voyageur, un nouvel étranger. Didier.

Nogueira, M. A. (2017). Capital cultural. In A. Catani et al. (Org.), Vocabulário Bourdieu (pp. 103-106). Autêntica.

Nogueira, M. A. (2008). Capital culturel. In A. Van Zanten (Org.), Dictionnaire de l'éducation (pp. 39-41). PUF.

Nogueira, M. A., \& Aguiar, A. M. de S. (2008). La formation des élites et l'internationalisation des études: Peut-on parler d'une "bonne volonté internationale"? Education et Sociétés, 1, 105-119.

Nogueira, M. A., Aguiar, A. M. de S., \& Ramos, V. C. C. (2008). Fronteiras desafiadas: A internacionalização das experiências escolares. Educação \& Sociedade, 29(103), 355-376.

Pasquier, D. (2005). Cultures lycéennes: La tyrannie de la majorité. Autrement.

Poullaouec, T., \& Lemêtre, C. (2009, avril/juin). Retours sur la seconde explosion scolaire. Revue Française de Pédagogie, 167, 5-11.

Reardon, S. F. (2011). The widening academic achievement gap between the rich and the poor: new evidence and possible explanations. In G. Duncan, \& R. Murnane (Org.), Whither opportunity? Rising inequality, schools, and children's life chances (pp. 91-115). Russel Sage Foundation.

Serre, D. (2012). Le capital culturel dans tous ses états. Actes de la Recherche en Sciences Sociales, 1, 4-1.

Soares, J. F., \& Collares, A. C. M. (2006). Recursos familiares e o desempenho cognitivo dos alunos do ensino básico brasileiro. Dados, 49(3), 615-650.

Van Zanten, A. (2014). L'école de la périphérie (A escola da periferia) revisitada. In N. Krawczyk (Org.), Sociologia do ensino médio (pp. 163-183). Cortez.

Van Zanten, A. (2007). Reflexividad y elección de la escuela por los padres de la clase media en Francia. Revista de Antropología Social, 16, 245-277.

Wagner, A. C. (2003). La bourgeoisie face à la mondialisation. Mouvements, 2, 33-39.

\section{Disponibilidade de dados}

Os dados subjacentes ao texto da pesquisa estão informados no artigo.

Como citar este artigo

Nogueira, M. A. (2021). O capital cultural e a produção das desigualdades escolares contemporâneas. Cadernos de Pesquisa, 51, Artigo e07468. https://doi.org/10.1590/198053147468

Recebido em: 02 JUNHO 2020 | Aprovado para publicação em: 16 SETEMBRO 2020 